\title{
Correction to: Electronic properties tuning of defective heterostructured CBN nanotubes by uniaxial pressure: a density functional study
}

\author{
Saed Salman ${ }^{1}$ (1) Najeh Rekik $^{2,3} \cdot$ Alaaedeen Abuzir $^{1} \cdot$ Jamal Suleiman $^{1}$
}

Published online: 6 December 2021

(c) The Author(s), under exclusive licence to Springer-Verlag GmbH, DE part of Springer Nature 2021

\section{Correction to: Applied Physics A (2021) 127:914}

https://doi.org/10.1007/s00339-021-05035-1

In the original publication of the article, one of Dr. Naje Rekik's affiliations was not included. The affiliation appears as below.

Physics Department, College of Science, University of Ha'il, Ha'il, Saudi Arabia

Publisher's Note Springer Nature remains neutral with regard to jurisdictional claims in published maps and institutional affiliations.

The original article can be found online at https://doi.org/10.1007/ s00339-021-05035-1.

Saed Salman

ssalman@kfu.edu.sa

1 Department of Physics, College of Science, King Faisal University, Al Ahsa 31982, Saudi Arabia

2 Present Address: Physics Department, College of Science, University of Ha'il, Ha'il, Saudi Arabia

3 Department of Chemistry, University of Alberta, Edmonton, AB T6G 2G2, Canada 